\title{
Agreement between cone-beam computed tomography and functional endoscopic sinus surgery for detection of pathologies and anatomical variations of the paranasal sinuses in chronic rhinosinusitis patients: A prospective study
}

\author{
Nafiseh Nikkerdar $\mathbb{D}^{1}$, Nastaran Eivazi $\mathbb{D}^{2, *}$, Mohana Lotfi $\mathbb{D}^{3}$, Amin Golshah $\mathbb{D}^{4}$ \\ ${ }^{1}$ Department of Oral and Maxillofacial Radiology, School of Dentistry, Kermanshah University of Medical Sciences, Kermanshah, Iran \\ ${ }^{2}$ Department of Otorhinolaryngology, School of Medicine, Kermanshah University of Medical Sciences, Kermanshah, Iran \\ ${ }^{3}$ Student Research Committee, School of Dentistry, Kermanshah University of Medical Sciences, Kermanshah, Iran \\ ${ }^{4}$ Department of Orthodontics, School of Dentistry, Kermanshah University of Medical Sciences, Kermanshah, Iran
}

\section{ABSTRACT}

Purpose: The diagnosis of chronic rhinosinusitis requires a comprehensive knowledge of the signs and symptoms of the disease and an accurate radiographic assessment. Computed tomography (CT) is the superior imaging modality for diagnosis of chronic rhinosinusitis. However, considering the lower dose and higher resolution of cone-beam computed tomography (CBCT) compared to CT, this study aimed to assess the agreement between the findings of $\mathrm{CBCT}$ and functional endoscopic sinus surgery (FESS).

Materials and Methods: This descriptive prospective study evaluated 49 patients with treatment-resistant chronic rhinosinusitis who were candidates for FESS. Preoperative CBCT scans were obtained before patients underwent FESS. The agreement between the CBCT findings and those of FESS was determined using the kappa correlation coefficient. The frequency of anatomical variations of the paranasal sinuses was also evaluated on CBCT scans.

Results: Significant agreement existed between pathological findings on CBCT scans and those of FESS, such that the kappa correlation coefficient was 1 for mucosal thickening, 0.644 for nasal deviation, 0.750 for concha bullosa, 0.918 for nasal polyp, 0.935 for ostiomeatal complex (OMC) obstruction, and 0.552 for infundibulum thickening. Furthermore, $95.9 \%$ of patients had 1 or more and $79.6 \%$ had 2 or more anatomical variations, of which nasal deviation was the most common $(67.3 \%)$.

Conclusion: Considering the significant agreement between the findings of CBCT and FESS for the detection of pathological changes in the paranasal sinuses, CBCT can be used prior to FESS to detect chronic rhinosinusitis and to assess anatomical variations of the OMC.(Imaging Sci Dent 2020; 50: 299-307)

KEY WORDS: Cone-Beam Computed Tomography; Endoscopy; Sinusitis

\section{Introduction}

Acute and chronic rhinosinusitis are highly prevalent debilitating conditions worldwide. ${ }^{1}$ Around $30 \%$ of Americans experience symptoms of rhinosinusitis. This condition results in medical costs of as much as 2 million dollars per year. ${ }^{2,3}$ Rhinosinusitis is characterized by inflammation

Received September 21, 2019; Revised February 19, 2020; Accepted February 20, 2020 * Correspondence to : Prof. Nastaran Eivazi

Department of Otorhinolaryngology, School of Medicine, Kermanshah University of Medical Sciences, Kermanshah, Building No. 1, Kermanshah University of Medical Sciences, Shahid Beheshti Boulevard, Kermanshah 6715847141, Iran

Tel) 98-9183311473,E-mail) nastaran_eivazi@yahoo.com of the nasal mucosa and paranasal sinuses and accumulation of fluid in the sinus cavity. ${ }^{1-4}$ Chronic rhinosinusitis refers to the persistence of this condition for more than 12 weeks. ${ }^{3}$ Several factors may be responsible for the occurrence of chronic rhinosinusitis. In particular, anatomical variations have been suggested to impair mucociliary flow and enhance the susceptibility to chronic rhinosinusitis. ${ }^{5,6}$ Ostiomeatal complex (OMC) obstruction prevents sinus drainage and leads to chronic sinusitis. The presence of anatomical variations in this region can further aggravate the obstruction. ${ }^{?}$

An accurate patient history, routine clinical examina-

Copyright (c) 2020 by Korean Academy of Oral and Maxillofacial Radiology 
tion of the ear, nose, and throat, and radiography can aid in reaching a definite diagnosis of chronic rhinosinusitis. Computed tomography (CT) is the standard imaging modality for assessment of the paranasal sinuses and is imperative prior to surgical treatment planning for patients with chronic rhinosinusitis. ${ }^{8}$ It can reveal pathologies in the sinus area, as well as anatomical variations of the OMC. However, its high patient radiation dose has led researchers to search for an alternative imaging modality with similarly high accuracy, but a lower patient radiation dose for maxillofacial assessments. ${ }^{9}$ Research with this goal led to the advent of cone-beam computed tomography (CBCT). In contrast to medical CT, the voxels are isotropic in CBCT and can be accurately used to measure maxillofacial structures from different angles. The resolution and quality of reconstructed CBCT images in the axial, sagittal, and coronal planes are the same. CBCT is superior to CT for maxillofacial imaging due to its high resolution and lower patient radiation dose. ${ }^{10} \mathrm{CBCT}$ has many applications in the oral and maxillofacial region and is commonly used to assess mandibular condyle lesions in patients with temporomandibular joint disorders or maxillofacial trauma; for implant planning and orthodontic patients; for evaluation of the anterior parts of the skull, the olfactory system, and airways; for the diagnosis of rhinosinusitis; assessment of mucosal thickness, detection of nasal septum deviation, concha hypertrophy, retention cysts in the head and neck region; and in the evaluation of pathologies and anatomical variations of the sinuses prior to functional endoscopic sinus surgery (FESS). ${ }^{11,12}$ A recent study also emphasized the need to evaluate otorhinolaryngologic symptoms when radiographic findings are identified on CBCT. ${ }^{13}$

The most common anatomical variations detectable on CBCT scans include septal deviation, concha bullosa, paradoxically angulated middle turbinate, agger nasi cell, Onodi cell, Haller cell, anterior clinoid process pneumatization, bulla ethmoidalis, and atelectatic uncinate process.

FESS is extensively performed for chronic rhinosinusitis patients who do not respond to pharmaceutical therapy, in order to resolve chronic sinonasal inflammation. ${ }^{14}$ The main goal of this approach is to clean the paranasal sinuses under direct vision, while preserving the physiological function of the sinuses and the nasal cavity. ${ }^{15}$

Although CT remains the superior imaging modality for detecting anomalies in the maxillofacial region and paranasal sinuses, Hashimoto et al. ${ }^{16}$ and Liang et al. ${ }^{17}$ showed that CBCT might be preferable for this purpose due to its lower patient radiation dose and higher resolution than CT. To the best of authors' knowledge, only 1 previous study has evaluated the agreement between the findings of CBCT and FESS. ${ }^{18}$ Thus, this study aimed to assess the agreement between CBCT and FESS findings regarding anatomical variations and pathologies of the paranasal sinuses to determine whether CBCT is an efficient technique for assessment of the paranasal sinuses in patients with chronic rhinosinusitis.

\section{Materials and Methods}

This interventional prospective study evaluated 49 patients with chronic rhinosinusitis presenting to a private ear, nose, and throat office to undergo FESS.

All procedures followed were in accordance with the ethical standards of the responsible committee on human experimentation (the study was approved by the ethics committee of Kermanshah University of Medical Sciences; ir.kums.ac.1394.357) and with the Helsinki Declaration of 1964 and later versions. Written informed consent was obtained from all patients prior to their enrollment.

The minimum sample size was calculated to be 49 patients according to the results of a pilot study conducted on 30 patients and the findings of Zojaji et al., ${ }^{18}$ Walter et al., ${ }^{19}$ and Sim and Wright, ${ }^{20}$ assuming a study power of 0.9 , a level of significance of 0.05 , and kappa values of 0.55 and 0.86 for the concha bullosa variable. The PASS software (NCSS, Kaysville, UT, USA) was used for sample size calculation.

The inclusion criteria were: 1) patients with a confirmed diagnosis of chronic rhinosinusitis according to the American Head and Neck Society criteria (facial pain, nasal congestion, fever, and impaired olfaction), ${ }^{5}$ 2) patients in whom this condition had lasted for more than 12 weeks with no response to medical and pharmaceutical therapy, and 3) patients with indications for medical imaging (CT/ CBCT) and FESS. Treatment-resistant cases were selected because they were candidates for FESS. Other patients did not need FESS because they were treated with other modalities, such as antibiotic therapy.

The exclusion criteria were sinus tumors (benign and malignant), acute rhinosinusitis, pregnancy, immunodeficiency, cystic fibrosis, age $<17$ years, history of FESS (due to possible deformation of anatomical variations), cardiac disease, history of rhinoplasty, and history of trauma to the face and sinuses. ${ }^{18}$

Eligible patients were selected by convenience sampling. Finally, 49 patients were included and CBCT scans (coronal, axial, and sagittal sections) were obtained of the paranasal sinus area in all patients using a NewTom VGI CBCT 


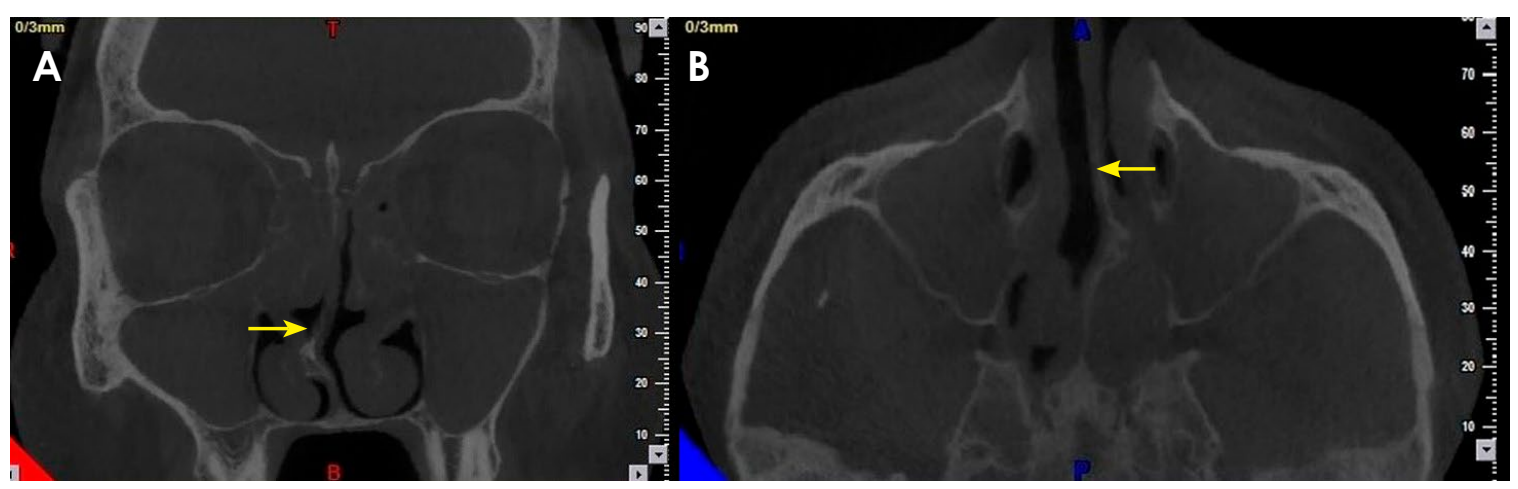

Fig. 1. Nasal septal deviations (arrows) are seen on the coronal (A) and axial (B) planes of cone-beam computed tomography.

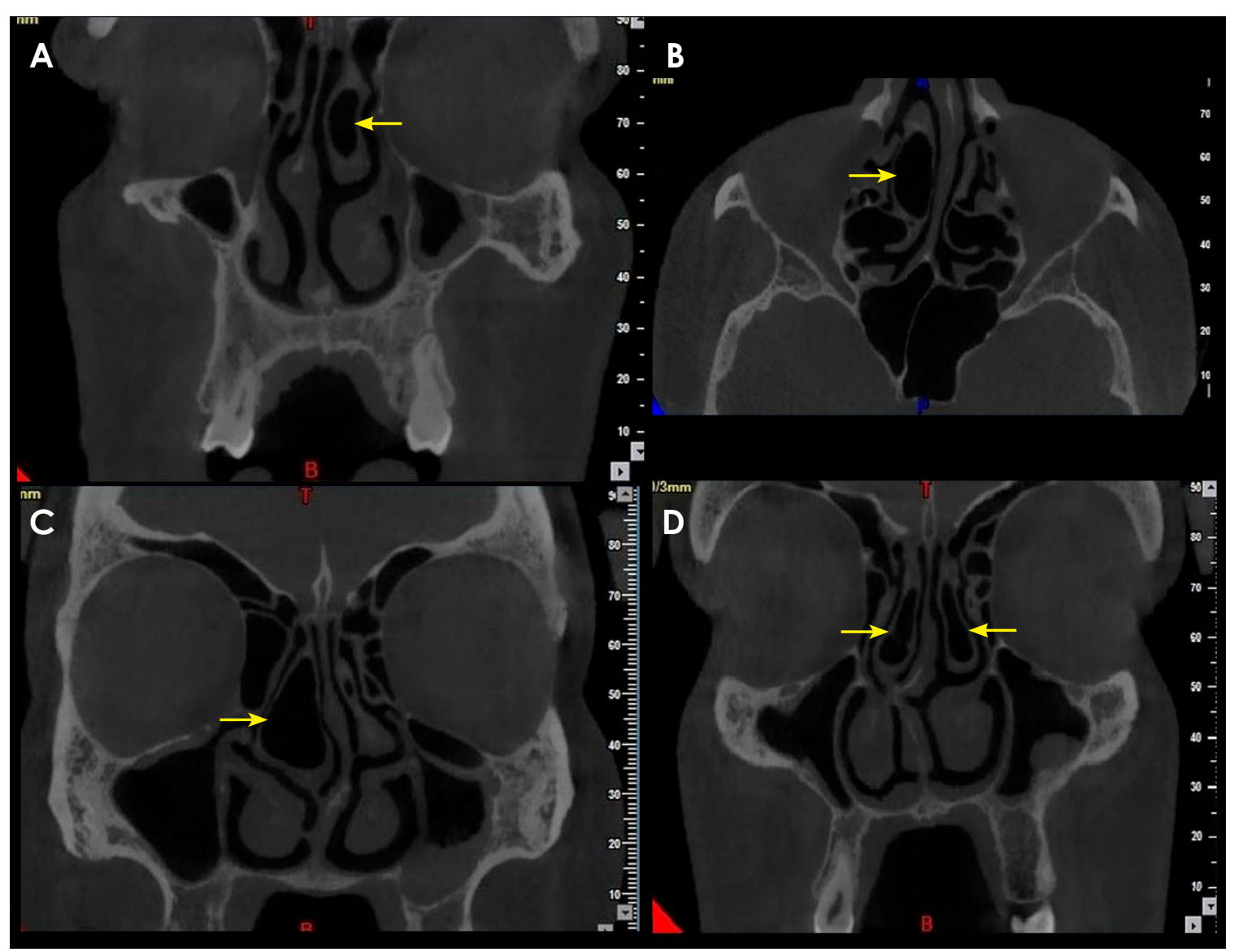

Fig. 2. Unilateral (A and B) and bilateral (C and D) concha bullosa (arrows) are seen on the coronal and axial planes of cone-beam computed tomography.

system (QR srl, Verona, Italy) with a spatial resolution of $300 \mu \mathrm{m}$ (voxel size, $0.3 \mathrm{~mm}$ ), a $15 \times 15 \mathrm{~cm}$ field of view, $110 \mathrm{kVp}$, and $59.78 \mathrm{mAs}$.

Two expert oral and maxillofacial radiologists evaluated the CBCT scans of patients on a LCD monitor (ASUS VS197DE, ASUS, ASUSTeK Computer Inc., Taiwan) with $1366 \times 768$ resolution using NNT Viewer software version
6.1 (QR srl, Verona, Italy). The paranasal sinuses were evaluated for pathologies including mucosa thickening, septal deviation, concha bullosa, nasal polyp, OMC obstruction, and infundibulum thickening, as well as anatomical variations including nasal deviation, agger nasi cell, bulla ethmoidalis, concha bullosa, Haller cell, Onodi cell, anterior clinoid process pneumatization, paradoxically an- 


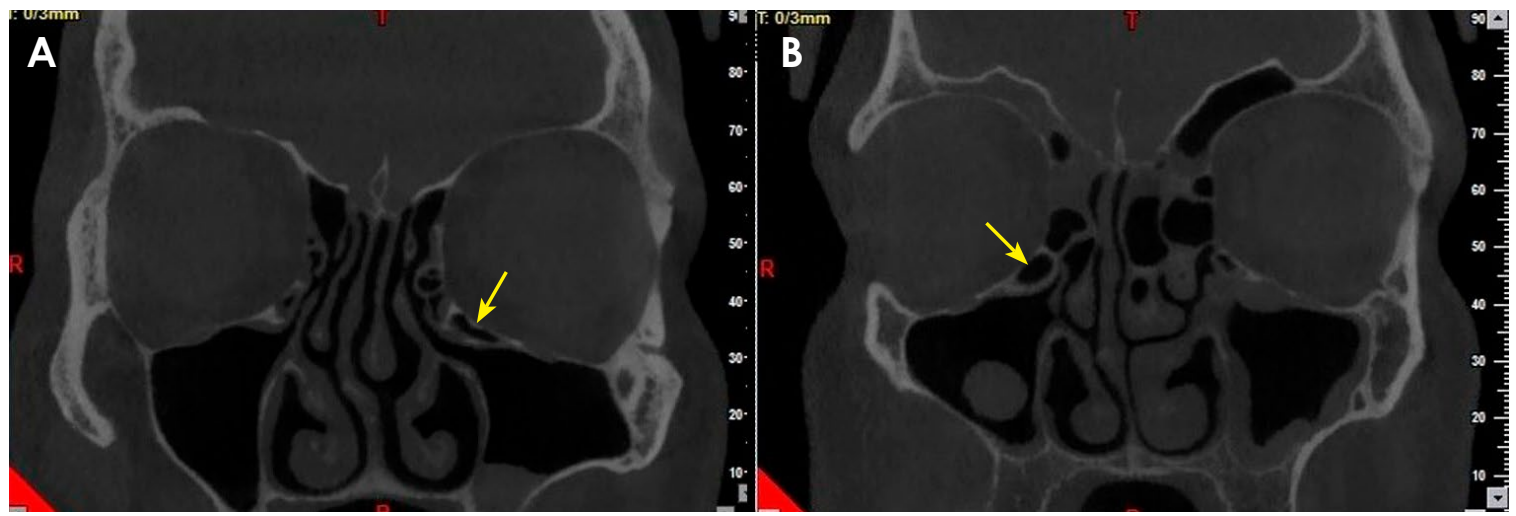

Fig. 3. A and B. Haller cells (arrows) are seen on the coronal plane of cone-beam computed tomography.

Table 1. Agreement between cone-beam computed tomography (CBCT) and functional endoscopic sinus surgery findings in patients with chronic rhinosinusitis (number and \%)

\begin{tabular}{|c|c|c|c|c|c|c|}
\hline Finding & CBCT & Endoscopy & No endoscopy & Total & Kappa coefficient & $P$ \\
\hline \multirow[t]{3}{*}{ Mucosal thickening } & Yes & $49(100.0 \%)$ & $0(0.0 \%)$ & $49(100.0 \%)$ & \multirow[t]{3}{*}{1} & \multirow[t]{3}{*}{-} \\
\hline & No & $0(0.0 \%)$ & $0(0.0 \%)$ & $0(0.0 \%)$ & & \\
\hline & Total & $49(100.0 \%)$ & $0(0.0 \%)$ & $49(100.0 \%)$ & & \\
\hline \multirow[t]{3}{*}{ Nasal deviation } & Yes & $38(95.0 \%)$ & $3(33.3 \%)$ & $41(83.7 \%)$ & \multirow[t]{3}{*}{0.644} & \multirow[t]{3}{*}{$<0.05$} \\
\hline & No & $2(5.0 \%)$ & $6(66.7 \%)$ & $8(16.3 \%)$ & & \\
\hline & Total & $40(100.0 \%)$ & $9(100.0 \%)$ & $49(100.0 \%)$ & & \\
\hline \multirow[t]{3}{*}{ Concha bullosa } & Yes & $17(73.9 \%)$ & $0(0.0 \%)$ & $17(34.7 \%)$ & \multirow[t]{3}{*}{0.750} & \multirow[t]{3}{*}{$<0.05$} \\
\hline & No & $6(26.1 \%)$ & $26(100.0 \%)$ & $32(65.3 \%)$ & & \\
\hline & Total & $23(100.0 \%)$ & $26(100.0 \%)$ & $49(100.0 \%)$ & & \\
\hline \multirow[t]{3}{*}{ Nasal polyp } & Yes & $24(96 \%)$ & $1(4.2 \%)$ & $25(51.0 \%)$ & \multirow[t]{3}{*}{0.918} & \multirow[t]{3}{*}{$<0.05$} \\
\hline & No & $1(4.0 \%)$ & $23(95.8 \%)$ & $24(49.0 \%)$ & & \\
\hline & Total & $25(100 \%)$ & $24(100.0 \%)$ & $49(100.0 \%)$ & & \\
\hline \multirow{3}{*}{$\begin{array}{l}\text { Ostiomeatal complex } \\
\text { obstruction }\end{array}$} & Yes & $39(97.5 \%)$ & $0(0.0 \%)$ & $39(79.6 \%)$ & \multirow{3}{*}{0.935} & \multirow{3}{*}{$<0.05$} \\
\hline & No & $1(2.5 \%)$ & $9(100.0 \%)$ & $10(20.4 \%)$ & & \\
\hline & Total & $40(100.0 \%)$ & $9(100.0 \%)$ & $49(100.0 \%)$ & & \\
\hline \multirow[t]{3}{*}{ Infundibulum thickening } & Yes & $38(92.7 \%)$ & $3(37.5 \%)$ & $41(83.7 \%)$ & \multirow[t]{3}{*}{0.552} & \multirow{3}{*}{$<0.05$} \\
\hline & No & $3(7.3 \%)$ & $5(62.5 \%)$ & $8(16.3 \%)$ & & \\
\hline & Total & $41(100.0 \%)$ & $8(100.0 \%)$ & $49(100.0 \%)$ & & \\
\hline
\end{tabular}

gulated middle turbinate, and atelectatic uncinate process. The findings were recorded using a checklist (Figs. 1-3). The CBCT scans were evaluated twice at a 2 -week interval to assess intraobserver agreement. To evaluate diagnostic agreement between radiologists (interobserver agreement), we computed the kappa score for various parameters.

Next, all patients who had indications for FESS underwent FESS under general anesthesia by an expert ear, nose, and throat specialist. The surgeon filled out the same checklist (Figs. 1-3) for paranasal sinus pathologies and anatomical variations based on his observations during the surgical procedure. The study checklists were filled out based on the presence or absence of findings.

The data of the 2 checklists were entered into SPSS for Windows version 20 (IBM Corp., Armonk, NY, USA) by a blinded examiner for statistical analysis. The agreement between the CBCT and FESS findings was assessed by calculating the kappa correlation coefficient. The level of significance was set at 0.05 . To interpret the obtained kappa values, the classification by Landis and $\mathrm{Koch}^{21}$ was used, where a kappa value $<0$ indicates poor agreement, values between 0.0 and 0.20 indicate slight agreement, values of 
Table 2. Diagnostic performance of the findings in the maxillary sinus on cone-beam computed tomographic images compared with sinus endoscopic surgery

\begin{tabular}{|c|c|c|c|c|c|c|c|c|c|}
\hline Finding & Sen & Spe & PPV & NPV & Acc & $+\mathrm{LR}$ & $-\mathrm{LR}$ & AUC & Power \\
\hline Mucosal thickening & 1 & - & 1 & - & 1 & - & - & - & - \\
\hline Nasal deviation & 0.95 & 0.66 & 0.92 & 0.75 & 0.89 & 2.85 & 0.07 & 0.80 & 0.90 \\
\hline Concha bullosa & 0.74 & 1 & 1 & 0.81 & 0.87 & $\operatorname{Inf}$ & 0.26 & 0.87 & 0.99 \\
\hline Nasal polyp & 0.96 & 0.95 & 0.96 & 0.95 & 0.96 & 22.85 & 0.04 & 0.96 & 1 \\
\hline Ostiomeatal complex & 0.97 & 1 & 1 & 0.90 & 0.98 & $\operatorname{Inf}$ & 0.02 & 0.98 & 1 \\
\hline Infundibulum thickening & 0.92 & 0.62 & 0.92 & 0.62 & 0.87 & 2.47 & 0.11 & 0.77 & 0.75 \\
\hline
\end{tabular}

Sen: sensitivity, Spe: specificity, PPV: positive predictive value, NPV: negative predictive value, ACC: accuracy, + LR: positive likelihood ratio, -LR: negative likelihood ratio, AUC: area under the receiver operating characteristic curve. Power refers to the power of the test for comparing cone-beam computed tomography compared with sinus endoscopic surgery

0.21-0.40 indicate fair agreement, values of 0.41-0.60 indicate moderate agreement, values of $0.61-0.80$ indicate substantial agreement, and values of 0.81-1.00 indicate almost perfect agreement.

\section{Results}

In total, 49 patients with chronic rhinosinusitis were evaluated in this study, of whom $40(81.6 \%)$ were men and $9(18.4 \%)$ were women. The mean age of the participants was $36.8 \pm 11.3$ years. The highest frequency of rhinosinusitis was found in patients in their fourth decade of life, followed by those in their third decade of life. The intraobserver agreement was found to be excellent (intraclass correlation coefficient $=1$ ). The kappa scores for the assessment of interobserver agreement were higher than 0.86 , implying satisfactory agreement between observers. The total duration of the study was approximately 18 months.

Table 1 shows the agreement between CBCT and FESS findings in patients with chronic rhinosinusitis. The observed agreement between CBCT and FESS for mucosal thickening was 1 (maximum). The observed agreement between CBCT and FESS for the detection of nasal deviation and concha bullosa was moderate and statistically significant $(P<0.05)$. The agreement between CBCT and FESS for nasal polyp and OMC obstruction was almost perfect and statistically significant $(P<0.05)$. The agreement between CBCT and FESS for infundibulum thickening was moderate and statistically significant $(P<0.05)$ (Table 1$)$.

The sensitivity, specificity, positive predictive value, negative predictive value, accuracy, positive likelihood ratio, negative likelihood ratio, area under the receiver operating characteristic curve, and test power are presented in Table 2. The high-test power results, except for the infundibulum thickening variable, indicate that the sample size of this
Table 3. Frequency of sinus pathologies in patients

\begin{tabular}{lcc}
\hline \multicolumn{1}{c}{ Pathology } & Number & Percentage \\
\hline Mucosal thickening & 49 & 100.0 \\
Septal deviation & 33 & 67.3 \\
Concha bullosa & 14 & 28.6 \\
Nasal polyp & 25 & 51.0 \\
Ostiomeatal complex obstruction & 39 & 79.6 \\
Infundibulum thickening & 41 & 83.7 \\
\hline
\end{tabular}

Table 4. Frequency of anatomical variations in patients

\begin{tabular}{lcl}
\hline \multicolumn{1}{c}{ Variation } & Number(\%) \\
\hline Nasal deviation & $33(67.3)$ & Right 22, left 11 \\
Agger nasi cell & $22(44.9)$ & \\
Bulla ethmoidalis & $17(34.7)$ & \\
Concha bullosa & $14(28.6)$ & Bilateral 5, unilateral 9 \\
Haller cell & $13(26.5)$ & \\
Onodi cell & $12(24.4)$ & \\
Anterior clinoid process & $9(18.4)$ & Bilateral 5, unilateral 4 \\
pneumatization & & \\
Paradoxically angulated & $7(14.3)$ & \\
middle turbinate & & \\
Atelectatic uncinated process & $6(12.2)$ & \\
Pneumatization of uncinate & $4(8.2)$ & \\
process & \\
\hline
\end{tabular}

study was sufficient.

Table 3 shows the frequency of sinus pathologies in patients. The CBCT scans of the 49 patients were also evaluated to determine the frequency of anatomical variations (Table 4). The results showed that $95.92 \%$ of patients had 1 or more and $79.6 \%$ of patients had 2 or more anatomical variations. Nasal deviation was the most common anatomical variation, followed by agger nasi cell and bulla eth- 
Table 5. Frequency of anatomical variations in previous studies (\%)

\begin{tabular}{|c|c|c|c|c|c|c|c|}
\hline & Our study & Dua et al. $^{41}$ & Tiwari et al. ${ }^{42}$ & Roman et al. ${ }^{36}$ & Aramani et al. ${ }^{35}$ & Adeel $^{43}$ & Riello et al. $^{39}$ \\
\hline Nasal deviation & 67 & 44 & 88.2 & - & 74.1 & 26 & 28.5 \\
\hline Agger nasi cell & 44.9 & 40 & 7 & - & 1.9 & - & 13.5 \\
\hline Bulla ethmoidalis & 34.7 & 14 & 63.5 & - & - & - & - \\
\hline Concha bullosa & 28.6 & 16 & 76.4 & 35.3 & 3.3 & 18.2 & 42.5 \\
\hline Haller cell & 26.5 & 16 & 3.5 & 25 & 1.9 & 9.1 & 8 \\
\hline Onodi cell & 24.4 & 6 & 1.6 & 8 & - & 7.8 & - \\
\hline $\begin{array}{l}\text { Anterior clinoid process } \\
\text { pneumatization }\end{array}$ & 18.4 & - & - & - & - & - & - \\
\hline $\begin{array}{l}\text { Paradoxically angulated } \\
\text { middle turbinate }\end{array}$ & 14.3 & 10 & 10.5 & 8 & 14.8 & 14.3 & 29 \\
\hline $\begin{array}{l}\text { Atelectatic } \\
\text { Uncinated process }\end{array}$ & 12.2 & - & - & - & - & - & - \\
\hline $\begin{array}{l}\text { Pneumatization of } \\
\text { uncinate process }\end{array}$ & 8.2 & - & - & 5 & 5.6 & 5.2 & 13 \\
\hline
\end{tabular}

moidalis. Pneumatization of the uncinate process had the lowest frequency of anatomical variations.

\section{Discussion}

This study assessed the agreement between the findings of CBCT and FESS regarding paranasal sinus pathologies and anatomical variations and showed significant agreement between their results.

Studies on the agreement between CBCT findings and FESS are lacking. ${ }^{18}$ However, many previous studies have compared the agreement between CT findings and surgical procedures in patients with chronic rhinosinusitis. ${ }^{22-24}$

The results of this study revealed significant agreement between the pathological findings of CBCT and FESS, aligning with the results of Agius ${ }^{22}$ and Pokharel et al. ${ }^{23}$ Woo et al. ${ }^{25}$ evaluated the efficacy of CBCT for preoperative assessment in endoscopic sinus surgery. They evaluated and compared the Lund-Mackay score before and after the operation and concluded that CBCT was an efficient modality for preoperative evaluation and diagnosis prior to surgical procedures of the paranasal sinuses. Their results, similar to ours, confirmed a significant agreement between the results of CBCT and surgery.

Woo et al. ${ }^{25}$ reported that the prevalence of chronic sinusitis was $66 \%$ in males and $44 \%$ in females. Balouchi et al. ${ }^{6}$ evaluated sinonasal polyposis and concluded that its prevalence in males was higher than that in females. Moreover, Flint et al. ${ }^{26}$ discussed that possible role played by environmental factors such as trauma and exposure to chemicals in the development of chronic rhinosinusitis. Since males are at higher risk of exposure to such environmental factors, they have a higher risk of this condition. In light of these findings, the higher proportion of men than women in the present study is justifiable.

Zojaji et al. ${ }^{18}$ evaluated the CBCT scans of 42 patients with chronic rhinosinusitis and found almost perfect agreement between CBCT and endoscopy for all the parameters evaluated, except for infundibulum thickening (kappa $=0.59$ ). However, the present study found substantial agreement between CBCT and FESS for nasal deviation and concha bullosa, and moderate agreement for infundibulum thickening. The kappa coefficients for mucosal thickening, nasal polyp, and OMC obstruction were $>0.8$ in the present study, which is in accordance with the results of Zojaji et al. ${ }^{18}$ The principal methodological difference between the present study and that of Zojaji et al. ${ }^{18}$ is that they considered FESS as the gold standard for diagnosis of rhinosinusitis. However, FESS has some shortcomings and is not accurate enough to be used as a gold standard. The present study assessed the agreement between CBCT and FESS findings to determine whether CBCT can serve as an alternative to CT for the diagnosis of paranasal sinus pathologies.

The almost perfect agreement between CBCT and FESS for mucosal thickening in the present study may be explained in light of the findings of some previous studies. For instance, Amodu et al. ${ }^{27}$ reported mucosal thickening of 1 or 2 sinuses on $98 \%$ of CT images. Rege et al. ${ }^{28}$ showed that mucosal thickening had the highest prevalence (66\%) of the abnormalities investigated on CBCT images of asymptomatic patients. Ritter et al. ${ }^{29}$ reported that CBCT 
detected pathological lesions in $56.3 \%$ of cases, and mucosal thickening was the most common CBCT finding. Khojastepour et al..$^{30}$ evaluated the CBCT scans of 281 patients who had undergone rhinoplasty. The frequency of mucosal thickening was $60.7 \%$. In line with our findings, some previous studies also showed that mucosal thickening had the highest prevalence of various abnormalities, and complete agreement existed between CBCT and FESS findings for its detection. Thus, CBCT images are highly valuable for detecting mucosal thickening of the paranasal sinuses.

Our study showed almost perfect agreement for OMC obstruction. Laine and Smoker ${ }^{31}$ stated that paranasal sinus endoscopy enabled direct observation of the OMC. Disease conditions in this region are also well detectable on CT images. Their findings confirmed our results regarding the almost perfect agreement (0.935) between CBCT and FESS findings for OMC obstruction. Our results showed almost perfect agreement between CBCT and FESS for nasal polyp, which is also in accordance with the results of Laine and Smoker. ${ }^{31}$

In the present study, the lowest agreement between CBCT and FESS was noted for infundibulum thickening (0.552). Stamberger and Kennedy ${ }^{32}$ described the infundibulum as a 3 -dimensional groove; the uncinate process forms its medial border, and the lamina papyracea forms its lateral border. In many cases, the border between the infundibulum and the frontal recess cannot be identified. Haung et al. ${ }^{33}$ reported that visualization of the frontal recess in endoscopic surgery is very difficult. Furthermore, detection of the frontal recess on $\mathrm{CT}$ scans requires images reconstructed in coronal, sagittal and axial sections. CBCT enables a 3-dimensional evaluation of images in all 3 planes. Thus, CBCT images can help in the evaluation of the frontal recess prior to sinus surgery. The difficulty of detecting the infundibulum during surgical procedures and the lack of samples with this variation may explain the low correlation coefficient for this finding.

Anatomical variations are other factors that cause rhinosinusitis. ${ }^{6}$ Such variations and anomalies play a role in the development of pathological lesions in the paranasal sinuses. ${ }^{34}$ OMC obstruction prevents sinus drainage and leads to chronic sinusitis. The presence of anatomical variations in this region increases the severity and extent of obstruction. ${ }^{7}$ Anatomical variations of the OMC include concha bullosa, septal deviation, uncinated process variation, agger nasi cell, Haller cell, and paradoxically angulated middle turbinate. ${ }^{35}$ Thus, $\mathrm{CT}$ is imperative prior to sinus surgery. At present, CBCT images are commonly used to detect anatomical variations of the sinonasal area due to the lower patient radiation dose than $\mathrm{CT}$ and the availability of multiplanar image reconstructions using $\mathrm{CBCT} .{ }^{36} \mathrm{CBCT}$ images are also used to describe the anatomy of bones in the sinonasal area. ${ }^{37}$

Due to the importance of detecting anatomical variations, a complete list of variations according to the available literature was compiled and evaluated; $79.6 \%$ of patients had 2 or more and $95.9 \%$ had 1 or more anatomical variations. This finding is in agreement with the results of some previous studies. For instance, Dasar and Gokce ${ }^{38}$ showed that $99.8 \%$ of patients had anatomical variations. Reillo et al. ${ }^{39}$ stated that $83.5 \%$ of patients had 1 or more anatomical variations, while Aramani et al. ${ }^{35}$ showed that $53.7 \%$ of patients had 2 or more anatomical variations. Table 5 presents the frequency of anatomical variations reported in several previous studies.

The current results revealed a significant correlation between the findings of CBCT and FESS for the detection of pathological changes in the paranasal sinuses. Furthermore, Hodez et al. ${ }^{40}$ stated that CBCT can serve as a gold standard for evaluation of the sinuses. Thus, CBCT may be used as an efficient alternative to CT for the preoperative evaluation of the paranasal sinuses in patients with chronic rhinosinusitis.

A small sample size and the lack of a comparison between CBCT and CT were among the limitations of the present study. Future studies with a larger sample size are required to compare the agreement between $\mathrm{CBCT}$ and $\mathrm{CT}$ findings for the detection of pathological changes in the paranasal sinuses.

In conclusion, the present study found strong agreement between the findings of CBCT and FESS regarding the paranasal sinuses. Thus, CBCT can be successfully used to detect chronic rhinosinusitis and to evaluate the presence of anatomical variations in the $\mathrm{OMC}$ in patients with chronic rhinosinusitis. CBCT can help in more accurate treatment planning and is an efficient modality for preoperative assessments before FESS.

\section{Conflicts of Interest: None}

\section{References}

1. Damm M, Quante G, Jungehuelsing M, Stennert E. Impact of functional endoscopic sinus surgery on symptoms and quality of life in chronic rhinosinusitis. Laryngoscope 2002; 112: 3105.

2. Krouse JH, Chadwick SJ, Gordon BR, Derebery MJ. Allergy and immunology: an otolaryngic approach. Philadelphia: Lippincott-Williams and Wilkins; 2002. p. 81-124. 
3. Lanza DC, Kennedy DW. Adult rhinosinusitis defined. Otolaryngol Head Neck Surg 1997; 117: S1-7.

4. Mischkowski R, Scherer P, Ritter L, Neugebauer J, Keeve E, Zöller J. Diagnostic quality of multiplanar reformations obtained with a newly developed cone beam device for maxillofacial imaging. Dentomaxillofac Radiol 2008; 37: 1-9.

5. Hwang PH, Irwin SB, Griest SE, Caro JE, Nesbit GM. Radiologic correlates of symptom-based diagnostic criteria for chronic rhinosinusitis. Otolaryngol Head Neck Surg 2003; 128: 48996.

6. Balouchi M, Berjis NA, Abbasi H, Talebi S. Pathologic findings in sinonasal polyposis and predisposing factors. J Isfahan Med Sch 2007; 24: 44-8.

7. Mamatha H, Shamasundar NM, Bharathi MB, Prasanna LC. Variations of ostiomeatal complex and its applied anatomy: a CT scan study. Indian J Sci Technol 2010; 3: 904-7.

8. Zinreich SJ. Rhinosinusitis: radiologic diagnosis. Otolaryngol Head Neck Surg 1997; 117: S27-34.

9. Scarfe WC, Farman AG, Sukovic P. Clinical applications of cone-beam computed tomography in dental practice. J Can Dent Assoc 2006; 72: 75-80.

10. De Vos W, Casselman J, Swennen GR. Cone-beam computerized tomography (CBCT) imaging of the oral and maxillofacial region: a systematic review of the literature. Int J Oral Maxillofac Surg 2009; 38: 609-25.

11. Çaglayan F, Tozoğlu U. Incidental findings in the maxillofacial region detected by cone beam CT. Diagn Interv Radiol 2012; 18: 159-63.

12. Shahab S, Nikkerdar N, Goodarzi M, Golshah A, Shooshtari SS. Diagnostic accuracy of cone beam computed tomography in detection of simulated mandibular condyle erosions. Dent Hypotheses 2015; 6: 97-103.

13. Horwitz Berkun R, Polak D, Shapira L, Eliashar R. Association of dental and maxillary sinus pathologies with ear, nose, and throat symptoms. Oral Dis 2018; 24: 650-6.

14. Sivaslı E, Şirikçi A, Bayazýt Y, Gümüsburun E, Erbagci H, Bayram M, et al. Anatomic variations of the paranasal sinus area in pediatric patients with chronic sinusitis. Surg Radiol Anat 2002; 24: 400-5.

15. Jones TM, Almahdi JM, Bhalla RK, Lewis-Jones H, Swift AC. The radiological anatomy of the anterior skull base. Clin Otolaryngol Allied Sci 2002; 27: 101-5.

16. Hashimoto K, Kawashima S, Kameoka S, Akiyama Y, Honjoya $\mathrm{T}$, Ejima $\mathrm{K}$, et al. Comparison of image validity between cone beam computed tomography for dental use and multidetector row helical computed tomography. Dentomaxillofac Radiol 2007; 36: 465-71.

17. Liang X, Jacobs R, Hassan B, Li L, Pauwels R, Corpas L, et al. A comparative evaluation of cone beam computed tomography (CBCT) and multi-slice CT (MSCT) Part I. On subjective image quality. Eur J Radiol 2010; 75: 265-9.

18. Zojaji R, Naghibzadeh M, Mazloum Farsi Baf M, Nekooei S, Bataghva B, Noorbakhsh S. Diagnostic accuracy of conebeam computed tomography in the evaluation of chronic rhinosinusitis. ORL J Otorhinolaryngol Relat Spec 2015; 77: 5560.

19. Walter S, Eliasziw M, Donner A. Sample size and optimal designs for reliability studies. Stat Med 1998; 17: 101-10.
20. Sim J, Wright CC. The kappa statistic in reliability studies: use, interpretation, and sample size requirements. Phys Ther 2005; 85: 257-68.

21. Landis JR, Koch GG. The measurement of observer agreement for categorical data. Biometrics 1977; 33: 159-74.

22. Agius AM. Chronic sinusitis in Malta - correlation between symptoms and CT scan. Rhinology 2010; 48: 59-64.

23. Pokharel M, Karki S, Shrestha BL, Shrestha I, Amatya RC. Correlations between symptoms, nasal endoscopy computed tomography and surgical findings in patients with chronic rhinosinusitis. Kathmandu Univ Med J (KUMJ) 2013; 11: 201-5.

24. Lund VJ, Mackay IS. Staging in rhinosinusitus. Rhinology 1993; 31: 183-4.

25. Woo WK, Shin WC, Jung DK, Lee YB, Lee SD. The usefulness of cone beam computed tomography in endoscopic sinus surgery. J Rhinol 2012; 19: 45-9.

26. Flint PW, Haughey BH, Lund VJ, Niparko JK, Robbins KT, Thomas JR, et al. Cummings otolaryngology - head and neck surgery. 6th ed. St. Louis: Mosby; 2014. p. 703-8.

27. Amodu EJ, Fasunla AJ, Akano AO, Daud Olusesi A. Chronic rhinosinusitis: correlation of symptoms with computed tomography scan findings. Pan Afr Med J 2014; 18: 40.

28. Rege IC, Sousa TO, Leles CR, Mendonça EF. Occurrence of maxillary sinus abnormalities detected by cone beam $\mathrm{CT}$ in asymptomatic patients. BMC Oral Health 2012; 12: 30.

29. Ritter L, Lutz J, Neugebauer J, Scheer M, Dreiseidler T, Zinser MJ, et al. Prevalence of pathologic findings in the maxillary sinus in cone-beam computerized tomography. Oral Surg Oral Med Oral Pathol Oral Radiol Endod 2011; 111: 634-40.

30. Khojastepour L, Mirhadi S, Mesbahi SA. Anatomical variations of ostiomeatal complex in CBCT of patients seeking rhinoplasty. J Dent (Shiraz) 2015; 16: 42-8.

31. Laine FJ, Smoker WR. The ostiomeatal unit and endoscopic surgery: anatomy, variations, and imaging findings in inflammatory diseases. AJR Am J Roentgenol 1992; 159: 849-57.

32. Stammberger HR, Kennedy DW. Anatomic Terminology Group. Paranasal sinuses: anatomic terminology and nomenclature. Ann Otol Rhinol Laryngol Suppl 1995; 167: 7-16.

33. Huang BY, Lloyd KM, DelGaudio JM, Jablonowski E, Hudgins PA. Failed endoscopic sinus surgery: spectrum of CT findings in the frontal recess. Radiographics 2009; 29: 177-95.

34. Kantarci M, Karasen RM, Alper F, Onbas O, Okur A, Karaman A. Remarkable anatomic variations in paranasal sinus region and their clinical importance. Eur J Radiol 2004; 50 : 296-302.

35. Aramani A, Karadi RN, Kumar S. A study of anatomical variations of osteomeatal complex in chronic rhinosinusitis patients CT findings. J Clin Diagn Res 2014; 8: KC01-4.

36. Roman RA, Hedeşiu M, Gersak M, Fidan F, Băciuţ G, Băciuţ M. Assessing the prevalence of paranasal sinuses anatomical variants in patients with sinusitis using cone beam computer tomography. Clujul Med 2015; 89: 419-21.

37. Mathew R, Omami G, Hand A, Fellows D, Lurie A. Cone beam CT analysis of Haller cells: prevalence and clinical significance. Dentomaxillofac Radiol 2013; 42: 20130055.

38. Dasar U, Gokce E. Evaluation of variations in sinonasal region with computed tomography. World J Radiol 2016; 8: 98 108. 
39. Riello AP, Boasquevisque EM. Anatomical variants of the ostiomeatal complex: tomographic findings in 200 patients. Radiol Bras 2008; 41: 149-54.

40. Hodez C, Griffaton-Taillandier C, Bensimon I. Cone-beam imaging: applications in ENT. Eur Ann Otorhinolaryngol Head Neck Dis 2011; 128: 65-78.

41. Dua K, Chopra H, Khurana AS, Munjal M. CT scan variations in chronic sinusitis. Indian J Radiol Imaging 2005; 15: 315 -
20.

42. Tiwari R, Goyal R. Study of anatomical variations on CT in chronic sinusitis. Indian J Otolaryngol Head Neck Surg 2015; 67: 18-20.

43. Adeel M, Rajput MS, Akhter S, Ikram M, Arain A, Khattak YJ. Anatomical variations of nose and para-nasal sinuses; CT scan review. J Pak Med Assoc 2013; 63: 317-9. 